\title{
AN EVALUATION OF A NEW FINISHING FILE ON THE BACTERIAL COUNT OF CANALS WITH DIFFERENT SIZES AND TAPERS: AN IN VITRO STUDY
}

\author{
Mohamed A. Hamed ${ }^{*}$, Wael H. Kamel ${ }^{* *}$, Ashraf S. Refaei*** and Mohamed E. Rokaya****
}

\begin{abstract}
Aim: This study was directed to evaluate the efficacy of XP endo finisher file to reduce the bacterial count in root canals prepared to different apical sizes and tapers. Materials and method: Mesiobuccal root canals of extracted human mandibular first molar teeth were selected in this study and prepared by using race rotary files into different apical sizes and tapers then the Xp endofinisher file used after these files. Results: A statistically significant difference in bacterial count was found between all groups after instrumentation where $(\mathrm{p} \leq 0.001)$. Also A statistically significant difference in bacterial count was found between all groups after using XPF where ( $\mathrm{p} \leq 0.001)$. Conclusion: Using Xp endofinisher file after canal preparation with small apical size was more effective in intracanal bacterial reduction than larger sizes.
\end{abstract}

\section{INTRODUCTION}

The goal of endodontic treatment is to control apical periodontitis ${ }^{(1)}$, a biofilm mediated infection of the root canal system through a combination of chemo mechanical approaches. Biofilms are microbial communities attached to the surfaces of root canal walls enveloped by extracellular polymeric substances ${ }^{(2)}$. One feature of bacteria in biofilm communities is increased resistance to antimicrobial agents ${ }^{(3)}$. Failure to completely eradicate intraradicular microorganisms may contribute to secondary endodontic infection ${ }^{(4)}$. Enterococcus faecalis, a gram-positive facultative anaerobe, has been isolated from primary endodontic infections and persistent endodontic infections $^{(5,6)}$. In the root canal environment, this bacterial species produces numerous virulence factors including gelatinase, cytolysin and adhesins, which play important roles in bacterial colonization, biofilm formation, and persistence in the root canal system. Because of these qualities, E. faecalis planktonic cells and biofilms are ideal for testing novel antimicrobial agents ${ }^{(7)}$. Complexity of root canal anatomy is also a deciding factor in successful endodontic therapy, as it resists penetration of irrigant solutions and other antimicrobial agents to enter into narrow, curved canals, fins, isthmuses and internal recess also physical limitation of irrigant penetration (vapor lock phenomena) due to closed system ${ }^{(8)}$. All of these factors contribute to failed endodontic therapy and persistent microbial species in the root canal systems so mechanical debridement in these limited spaces is ideal for reduction of this bacterial load by itself and by allowing irrigant penetration deeper into the canal, finally by irrigant agitation that improve its antibacterial properties ${ }^{(9)}$.

Hence the development of different irrigant activation methods starting from ultrasound by Richman till the development of Xp endofinisher file by FKG, these methods and others aid in bacterial load reduction through irrigant activation (10). Thus, the experimental design of the present

\footnotetext{
* Demonstrator of Endodontic, faculty of Dentistry, al Azhar University, Assuit.

** Professor and Head of Endodontic Department, Faculty of Dentistry for girls al Azhar University. Cairo.

**** Assistant professor and Head of Endodontic Department, Faculty of dentistry boys, al Azhar University. Cairo.

**** Lecturer of Endodontic, Faculty of Dentistry, al Azhar University, Assuit.
} 
study aimed to evaluate the efficacy of $\mathrm{XpF}$ as an irrigant activator in removing intracanal bacterial population after preparation of root canals into different sizes and taper.

\section{MATERIALS AND METHODS}

\section{1- Selection and preparation of samples:}

A total of seventy-five human mandibular first molar teeth were used in this study. The teeth were examined clinically and radiograpically for any defects like cracks and fishers and previous root canal therapy were discarded and root canal curvature within range of $15-35^{\circ}$ was selected according to Schneider technique. Any carious tooth structures were removed then rebuilding was done using resin based composite material due to its non-antibacterial action then access cavity was done and patency of the canals was maintained using size \# 10 and size \# $15 \mathrm{k}$ file,then enlarge the canal to size \#20 then the teeth were rinsed with copious amount of saline then the samples were irradiated using gamma rays (Cobalt 60 irradiator with dose rate of $1.774 \mathrm{KGY}$ with total dose of $25 \mathrm{KGY}$.) then checking of teeth sterility were done by injecting saline solution into canal space and paper point sample was taken and cultured in broth agar ,absence of turbidity indicate serialization of teeth.

\section{2- Preparation and contamination of samples:}

The E. faecalis was prepared by growing Pure $E$. faecalis on a bile-esculin plate for 24 hours at $37^{\circ} \mathrm{C}$. The inoculation of root canals with E. faecalis was done using a sterile plastic syringe with a modified $30 \mathrm{~g}$ endodontic side vented needle (trimmed to the level of the side perforation converting it into an openended needle) to allow for the bacterial suspension to be pushed down into the apical part of root canal. Each root canal was completely filled with $0.5 \mathrm{ml}$ of E. faecalis suspension, then a sterile size $\# 15 \mathrm{~K}$ files was inserted inside the canal to full working length for uniform dispersion. The inoculated teeth were then placed inside a sterile plastic tube then
$4 \mathrm{ml}$ of saline solution were added and the tube was sealed with its screw cap then placed in a tube rack then the tubes were then incubated for $48 \mathrm{~h}$ at $37^{\circ} \mathrm{C}$ and $100 \%$ humidity, this were allowed for bacteria to multiply and proliferate.

\section{3- Root canal instrumentation and grouping:}

Samples were randomly grouped into main five groups according to final apical size and taper reached into Group A: size \# 25 and taper 6\%, Group B: size \# 30 and taper 4\%, Group C: size \# 30, and taper 6\%: Group D: size \# 35 and taper 4\% and Group E: size \# 40 and taper 4\%. Root canals in each group were instrumented using Race rotary files (FKG Dentaire S.A.) according to manufacturer instructions, Irrigation was accomplished with total amount of irrigant per canal was $7 \mathrm{ml}$. of saline solution irrelevant of the number of files using side perforated needle inserted to $2 \mathrm{~mm}$. from working length without locking in the canal. Then the second bacterial sample was taken. Following instrumentation, Cleaning was accomplished using a combination of saline solution and $\mathrm{XpF}$ then the third bacterial sampling was done.

\section{RESULTS}

The mean and standard deviation values were calculated for each group. There is no statistically significant difference before instrumentation in bacterial count between all groups where ( $p=0.09$ ), while there is a statistically significant difference in bacterial count between all groups after instrumentation where $\mathrm{p} \leq 0.001$. Where no statistically significant difference in bacterial count between Group1 and Group3. The highest mean of bacterial count was found in (Group 2) followed by (Group 4), (Group 5) and (Group 3). While the least bacterial count was found in (Group 1). Finally, after using XPF there is a statistically significant difference in bacterial count between all groups where $(\mathrm{p} \leq 0.001)$ with no statistically significant difference in bacterial count between Group3 
and Group4. The highest mean of bacterial count was found in (Group 5) followed by (Group 4), (Group 3) and (Group 2). While the least bacterial count was found in (Group 1).

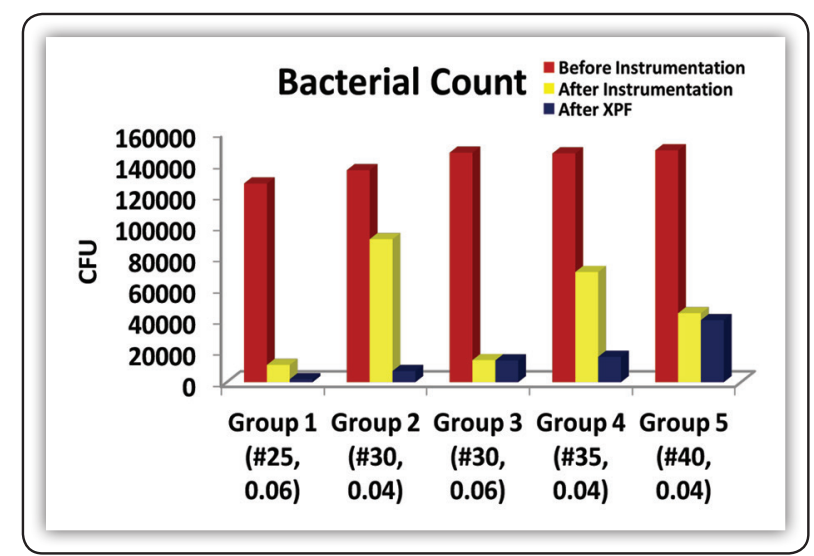

FIG (1) A bar chart representing bacterial count throughout the study for all groups.

\section{DISCUSSION}

Root canal disinfection is one of the main clinical challenges in endodontic therapy, it is a challenge due to the physical limitations of irrigation within a closed system, anatomical root complexities and bacterial accumulation in the biofilms ${ }^{(11,12)}$. Natural teeth were selected in this study to simulate more closely the clinical situation ${ }^{(13)}$. The mandibular molars were used in this study because they are the most common teeth that receive endodontic therapy, also the mesio buccal root canals exhibit higher anatomical complexity ${ }^{(14)}$. All mesiobuccal canals were enlarged to a size \#20 to allow easy insertion of paper points during pre-instrumentation sampling process. Size \#20 was selected rather than size \#15, because during the pilot study it was impossible to insert a size \#15 paper point prior to preparation for the bacterial sampling process. The bacteria selected for this study was E. faecalis, because it is commonly found in endodontic infection and its ability to enter dentinal tubules easily, survive under adverse environmental conditions, does not require support from other bacteria and is relatively easy to culture and manipulate ${ }^{(15,16)}$. Furthermore, Bileesculin media was used because it is a selective medium for the detection of E. Faecalis ${ }^{(17)}$. In this study the turbidity level adjusted to that of 0.5 McFarland standard $\left(1.5 \times 10^{8} \text { bacteria/ml }\right)^{(18)}$, and because the microorganisms were also detected in the pilot study at this level, this was followed by incubation period $48 \mathrm{hrs}$.to ensure deeper penetration of E. Faecalis into dentinal tubules ${ }^{(19)}$. Bacterial sampling was done by using three successive absorbent paper point size \#20 as described by Siqueira et $a^{(20)}$. The plate culture method was used as it is the frequent method in bacterial reduction studies $^{(21,22)}$, which is cheap and readily available, although molecular method (PCR) has been suggested as the most sensitive bacterial detection tests, other study showed similar results using the molecular and plate culture techniques ${ }^{(23)}$. In this study the saline solution was used as irrigation due to its non-bactericidal action ${ }^{(24)}$, so the results were indicated only the effects of mechanical instrumentation technique. The following apical diameter and tapers were evaluated (size \# 25 taper 0.06 , size \# 30 taper 0.04 , size \# 30 taper 0.06 , size \# 35 taper 0.04 and size \#40 taper 0.04) because these are the most commonly reached apical diameter during preparation of molar canals. Moreover, size \#25 taper 0.04 was not selected for evaluation in this study for the following reasons: The minimum taper that mimics a conventional preparation using ISO standardized hand instruments in a step back technique is a taper $0.05^{(25)}$, it has also been previously been established that The size \#25 taper 0.04 didn't allow for easy return of irrigant material and doesn't allow for fine irrigation needle penetration to within 1-2 mm. from working length ${ }^{(26)}$. Finally, it will be nearly impossible to properly obturate canals of a size \#25 0.04 due to limited penetration of the obturating instrument (plugger or spreader) ${ }^{(27)}$. On the other hand the size \# 35 and size \# 40 taper 0.06 not selected in this study as they are not commonly used in preparation of mandibular molar because of increase possibility 
of dentin weakening and stripping perforation ${ }^{(28)}$. In this study there was no statistically significant difference in bacterial count before instrumentation between all groups, this confirmed a standardized starting point for evaluation. When comparing the bacterial counts after instrumentation between the different sizes it was founded that the 0.06 taper groups (group 1 and 3) showed the least amount of bacterial count when compared to other groups. This difference was statistically significant. This can be attributed to the difference in taper between the instruments. Notably, 0.06 taper allow for deeper penetration of irrigation needle and easy return and flow dynamics ${ }^{(29)}$. This in agreements with a lot of research ${ }^{(30,31)}$ and in disagreement with Moshari A, ${ }^{(32)}$, and Elayouti et al. ${ }^{(33)}$. This may be due to different irrigation materials i.e. (sodium hypochlorite, EDTA), the volume of irrigant and irrigation protocols, while in our research only saline was used. Also, in the publication by Elayouti et al. a different instrument was evaluated. Furthermore, in these contradicting publications the teeth evaluated were autoclaved not irradiated using gamma radiation, this has proven to alter the nature of dentin ${ }^{(34)}$. Moreover, when comparing the bacterial count after using the XPF, there was a statistically significant difference in bacterial count between all groups, with the highest mean of bacterial count was found in (size \#40 taper 0.04) followed by (size \#35 taper 0.04), (size \#30 taper 0.06) and (size \#30 taper $0.04)$. While the least bacterial count was found in (size \#25 taper 0.06). As the XpF instrument strictly cleans by mechanical scrapping ${ }^{(10)}$. This difference can be attributed to the smaller canal size at the critical apical part of the preparation that leads to more contact of the $\mathrm{XpF}$ with the canal walls hence leading to more scrapping action, loosening of debri and more bacterial reduction. It seems to be unlike PUI that requires large canal space for cavitation and micro streaming the $\mathrm{XpF}$ instrument requires more intimate contact with the canal walls to achieve effective cleaning ${ }^{(35)}$.

\section{CONCLUSION}

Within the parameter of this study The $\mathrm{XpF}$ is an effective tool in reducing the intracanal bacteria, also using $\mathrm{XpF}$ after canal preparation with small apical size was more effective in intracanal bacterial reduction than larger sizes.

\section{ACKNOWLEDGMENT}

I would like to thank Dr Amany Mohamed Twfeek, assistant professor of microbiology, faculty of medicine for girls Alazhar University Cairo, for assistance and guidance in microbiological work of this research.

\section{REFERENCES}

1. Ferrer L, Bejarano I, Ruiz L, Baca P. Reduction in Enterococcus faecalis counts - a comparison between rotary and reciprocating systems. Int Endod J 2014, 47, 380-6.

2. Miller, W.: An Introduction to the Study of the Bacteria-pathology of the Dental Pulp, Dental Cosmos 1894, 36: 505-28.

3. Onderdonk, T. The treatment of unfilled root canals. Internet. D. J. 1901, 22:20.

4. Morse, F, and Yates, M. Follow-up studies of root filled teeth in relation to bacteriologic findings. JADA 1941 , 28:956.

5. Kakehashi S, Stanley H, Fitzgerald R ,The effects of surgical exposures of dental pulps in germ-free and conventional laboratory rats. Oral Sur., Oral Med., Oral Path 1965;20(3):340-9.

6. Naidorf I, inflammation and infection of pulp and periapical tissue; oral Surg 1972, 34,486-96.

7. Sundiqvist $\mathrm{G}$, Jhonson E, Sjogran U, prevalence of black pigmented bacteriods in root canal infections, J Endod 1989,15,13-9

8. Weine F. Endodontic Therapy, 5th edn. St Louis: MosbyYearbook Inc., 1996: 243.

9. Abou-Rass M, Piccinino M. The effectiveness of four clinical irrigation methods on the removal of root canal debris. Oral Surg Oral Med Oral Pathol 1982; 54:323-8.

10. FKG Dentaire SA. XP-endo Finisher [brochure]. La Chaux-de-Fonds: FKG Dentaire SA. Available from: http:// www.fkg.ch/sites/default/ files/fkg_xp_endo_brochure_ en_vb.pdf. 
11. Cesar G, Ana A, Natalia N,Veronica O and Nestor C., Effect of Apical Size and Taper on Volume of Irrigant Delivered at Working Length with Apical Negative Pressure at Different Root Curvatures, J Endod 2013;39:119-24.

12. Tay C, Samantha Y, Jeen N, Victoria S and Kai S, Matrix Metalloproteinase Inhibitor as an Antimicrobial Agent to Eradicate Enterococcus faecalis Biofilm, doi. org/10.1016/j.joen 2015.01.032.

13. Weine F. Endodontic Therapy, $6^{\text {th }}$ ed. St. Louis, Missouri: Mosby, 2004

14. Siqueira F, et al, Correlative Bacteriologic and MicroComputed Tomographic Analysis of Mandibular Molar Mesial Canals Prepared by SelfAdjusting File, Reciproc, and Twisted File Systems J Endod 2013;39:1044- 50.

15. Marlos B, Antimicrobial Susceptibility and Characterization of Virulence Genes of Enterococcus faecalis Isolates from Teeth with Failure of the Endodontic Treatment,.doi. org/10.1016/j.joen 2016.03.015

16. Love R, Enterococcus faecalis -a mechanism for its role in endodontic failure, Int Endod J 2001, 34, 399-405.

17. Shirley, L and Quinn, P., use of bile-esculin agar for rapid differentiation of Enterobacteriaceae, $\mathrm{j}$ clin microbiol 1975, 1, (5), 440-3.

18. Blanscet L, Patricia A. and Gary G. An Agar Diffusion Comparison of the Antimicrobial Effect of Calcium Hydroxide at Five Different Concentrations with Three Different Vehicles, J Endod 2008; 34:1246-8.

19. Siqueira F,Achado $m$, Lveira M, Lopes H \&De Uzeda M, Evaluation of the effectiveness of sodium hypochlorite used with three irrigation methods in the elimination of Enterococcus faecalis from the root canal, in vitro, Int Endod J 1997, 30, 279-82.

20. Siqueira F, Rocas I, Amauri F and Kenio C., Chemo mechanical Reduction of the Bacterial Population in the Root Canal after Instrumentation and Irrigation with 1\%, 2.5\%, and 5.25\% Sodium Hypochlorite, J Endod 2000. 26, (6), $331-4$.

21. Alves F, et al. Bacterial community profiling of cryogenically ground samples from the apical and coronal root segments of teeth with apical periodontitis. J Endod, 2009, 35, 486-92.

22. Tewari K. \&etal, mechanical reduction of the intracanal enterococcus Faecalis population by hyflex $\mathrm{cm}, \mathrm{k} 3 \mathrm{xf}$, protaper next, and two manual instrument systems: an in vitro comparative study, J Invest and Clin Dent 2014, 0, 1-6.
23. Alves F, et al. Quantitative molecular and culture analyses of bacterial elimination in oval-shaped root canals by a single-file instrumentation technique. Int Endod J 2012; 45:871-7.

24. Demiryurek E, ElifKalyoncuo G, EsraDuran, Coban A,Tanriverdi C Efficacy of different instrumentation techniques on reducing Enterococcus faecalis infection in experimentally infected root canals, J D Sci (2013), http:// dx.doi.org/10.1016/ j.jds 2012.03.024

25. Cohen's, pathways of the pulp, $11^{\text {th. }}$ edition, Elsevier Inc. 2016,241

26. Whitworth J, Methods of filling root canals: principles and practices. Endod Top 2005, 12:2-24.

27. Wu K, Roris A, Barkis D, Wesselink P: Prevalence and extent of long oval canals in the apical third,Oral Surg Oral Med Oral Pathol Oral Radiol Endod 2000, 89:739-43.

28. Rollison S, Barnett F, Stevens R. Efficacy of bacterial removal from instrumented root canals in vitro related to instrumentation technique and size. Oral Surg Oral Med Oral Path Oral Radio Endod 2002; 94:366 -71.

29. Boutsioukis C, Gogos C, Verhaagen B, Versluis M, Kastrinakis E, van der Sluis L. The effect of apical preparation size on irrigant flow in root canals evaluated using an unsteady Computational Fluid Dynamics model. Int Endod J 2010, 43, 874-81.

30. Park E, Shen Y, Haapasalo M irrigation of the apical root canal. Endod topic 2012; 27:54-73

31. Arvaniti I , Khabbaz M . Influence of root canal taper on its cleanliness: a scanning electron microscopic study. J Endod 2011; 37: 871

32. Moshari A et al,reduction of enterococcus faecalis in curved root canals after various sizes and tapers of canal preparation ,j conserve dent 2015;18,4,306-9.

33. Elayouti A, Dima E, Judenhofer M, Lost C, Pichler B. Increased apical enlargement contributes to excessive dentin removal in curved root canals: A stepwise microcomputed tomography study. J Endod 2011; 37:1580-4.

34. Delia S., Kuniko S, Joan F., Grayson W., Sally J., Effect of sterilization by gamma radiation on nano-mechanical properties of teeth, dental materials 2008, 24, 1137-40.

35. Van der Sluis, L., Wu, M. and Wesselink, P. The evaluation of removal of calcium hydroxide paste from an artificial standardized groove in the apical root canal using different irrigation methodologies. Int Endod J 2007; 40: 52- 7. 
